NBER WORKING PAPER SERIES

UNCOVERING SOME CAUSAL

\title{
RELATIONSHIPS BETWEEN PRODUCTIVITY \\ GROWTH AND THE STRUCTURE OF \\ ECONOMIC FLUCTUATIONS: A \\ TENTATIVE SURVEY
}

Philippe Aghion

Gilles Saint-Paul

Working Paper No. 4603
NATIONAL BUREAU OF ECONOMIC RESEARCH
1050 Massachusetts Avenue
Cambridge, MA 02138
December, 1993

This paper is part of NBER's research program in Economic Fluctuations. Any opinions expressed are those of the authors and not those of the National Bureau of Economic Research. 


\title{
UNCOVERING SOME CAUSAL RELATIONSHIPS BETWEEN PRODUCTIVITY \\ GROWTH AND THE STRUCTURE OF ECONOMIC FLUCTUATIONS: A TENTATTVE SURVEY
}

\begin{abstract}
This paper discusses recent theoretical and empirical work on the interactions between growth and business cycles. One may distinguish two very different types of approaches to the problem of the influence of macroeconomic fluctuations on long-run growth. In the first type of approach, which relies on learning by doing mechanisms or aggregate demand extemalities, productivity growth and direct production activities are complements. An expansion therefore has a positive long-run effect on total factor productivity. In the second type of approach, hereafter labeled "opportunity cost" or "learning-by-doing", productivity growth and production activities are substitutes. The opportunity cost of some productivity improving activities falls in a recession, which has a long-run positive impact on output This does not mean, however, that recessions should on average last longer or be more frequent, since the expectation of furure recessions reduces today's incentives for productivity growth. We also briefly discuss some empirical work which is mildly supportive of the opportunity cost approach, while showing that it can be reconciled with the observed pro-cyclical behavior of measured total factor productivity. We also describe some theoretical work on the effects of growth on business cycles.
\end{abstract}

Philippe Aghion

Nuffield College

Oxford OX1 INF

UNITED KINGDOM
Gilles Saint-Paul

ENS

48 Boulevard Jordan

Paris 75014

FRANCE 


\section{Introduction}

Productivity growth and the business cycle had long been recognized as being closely interrelated. Yet, for several decades, the two phenomena have been investigated separately by the economic literature: on the one hand, business cycle theorists would analyse detrended data and then possibly introduce the trend as exogenous to the cycle; on the other hand, growth theorists would focus on the existence and stability of a long-run deterministic growth path.

However, the emergence in the 1980's of the real business cycle literature, emphasising productivity shocks as a main driving force behind cyclical fluctuations, called into question the traditional division of macroeconomic theory between trend and cycles, and suggested a retum to the Schumpeterian view of growth and cycles as a unified phenomenon.

This paper is an attempt to show why the endogenous growth approach, and particularly the Schumpeterian models of (vertical) technological change, provides a natural framework for a better theoretical and empirical understanding of the causal relationships between trend and fluctuations.

The paper is organized as follows: Section 2 briefly reviews the parallel but separate evolutions of growth and cycle theories prior to the emergence of the endogenous growth literature. Section 3 presents a first attempt at generating endogenous productivity growth in models of business cycles. Section 4 discusses the Schumpeterian idea that recessions may favour the occurrence of (aggregate) productivity improvements on the basis of recent theoretical and empirical contributions. Section 5 develops a Schumpeterian model of cyclical growth that illustrates how the rate of long-run productivity growth depends upon the structure of the business cycle (that is, upon the magnitude and frequency of economic fluctuations), both when productivity growth is procyclical as in Section 3 or countercyclical 
as argued in Section 4. Finally Section 6 concludes this (very preliminary and incomplete) survey by mentioning some recent attempts at understanding the reverse causality from productivity growth to economic fluctuations; one such attempt uses some recent extension of the neo-Schumpeterian paradigm emphasising the complementarity between fundamental and secondary innovations and its implication for the existence of Schumpeterian waves.

\section{A Fer Historical Benchmarks}

The first consistent madel of the trade cycle - the so-called accelerator-multiplier - was developed as an extension of Keynes' fixed-price paradigm where the disequilibrium between demand and supply on the goods market was to be resorbed through quantity adjustments, namely through investments in new capacities. Assuming that current investment is equal to the difference between the desired level of capital stock next period $\mathrm{K}_{\mathrm{t}+1}^{+}$, and its current level $K_{1}{ }^{\prime}$ and that the desired level $K_{1+1}^{+}$is proportional to the expected demand next period, $Y_{1+1}^{+}$, one would get: $\mathrm{L}_{1}=v . Y_{1+1}^{+}-\mathrm{K}_{1}=v\left(Y_{1+1}^{+}-Y_{2}\right)$. This would determine the supply response of investment to an expected increase in demand, i.e. the so-called accelerator effect.

Conversely, a current increase in investment would induce a bigger increase in total demand "next period" according to the multiplier effect: $Y_{t+1}=\frac{I_{t}-I_{t-1}}{1-c}$, where $\mathrm{c}$ is the aggregate propensity to consume.

Eliminating the $\mathrm{L}_{4}$ 's between these two equations would lead to the well-known secondorder equation describing the oscillator of Samuelson. As Kaldor (1954) already noticed, the oscillator model had no trend component in it. "As a pure cyclical model, it had therefore

1 Thus, it is implicitly assumed that investment is not instantaneous and requires a one period lag to be put in place. 
little resemblance to the cyclical fluctuations in the real world, where successive booms carried production to successively higher levels".

The absence of growth component in the oscillator model might seem somehow paradoxical for those who remember that the first balanced growth model by Domar (1945) had also been formulated in terms of the multiplier/accelerator! The main point there was to derive a necessary and sufficient condition under which an increase in capacity subject to the accelerator mechanism would exactly match the increase in demand induced by the multiplier mechanism. ${ }^{2}$ However, the existence of a sustainable growth path was left unexplained. The same criticism also applies to more recent versions of the oscillator model (Hicks, 1950; Kalecki, 1938 ...) that extended Samuelson's paradigm by superimposing a linear trend on the original model without altering its basic properties. The trend itself was left unexplained, but rather introduced from the outside either by assuming a linear percentage growth in population or by introducing an exogenous source of technical progress.

Goodwin (1967) is probably the first model of cyclical growth, where the occurrence of economic fluctuations was modelled as a deterministic consequence of the growth process and more specifically of the variations in income distribution (between wages and profits) this process induces over time. ${ }^{3}$

2 At any point in time, the increase in production capacity $\Delta Q^{2}$ and the increase in demand $\Delta Q^{d}$ must evolve according to:

$$
\Delta Q^{s}=1 / v \text { (accelerator) }
$$

(2) $\Delta Q^{d}=\Delta 1 \%$ (multiplier), where $\Delta \mathrm{I}$ denotes the current variation in investment.

Balanced growth thus requires $\Delta Q^{s} \equiv \Delta Q^{d}$, i.e. $\Delta 1 / 1=g=1 /$.

3 The business cycle results in Goodwin (1967) follows from the following predatorprey relationship between unemployment (i.e. wages) and profits: when the economy is in expansion, growth is high and so is investment, with the effect of decreasing 
The post-Keynesian models mentioned above were all non-market clearing models, where economic fluctuations resulted, either from capacity adjustments in the goods market in accelerator-multiplier models, or from employment adjustments in the labour market in the Goodwin model. More recent growth or business cycle models have gotten rid of non-market clearing assumptions, yet without solving the difficulty of explaining the growth trend and its current relationship with the business cycle. This is true of Solow's (1956) seminal contribution [and its various extensions prior to the endogenous growth literaturet] where again no long-run trend would obtain in the absence of population growth or of exogenous technical progress. This is also true of business cycle models developed in a market clearing context, either on the basis of unanticipated monetary shocks and informational rigidities (as in Lucas (1972)), or resulting from strong non-linearities in intertemporal preferences (as in Benhabib-Day (1983) and Grandmont (1985)), or arising from the combination between temporary productivity shocks and adjustment lags or inter-sectoral inertia (as in the real business cycle literature pioneered by Kydland-Prescott (1982) and Long-Plosser (1983): none of these models were concerned with explaining the existence of a trend in (causal) relation to the business cycle.

However, the real business cycle approach came very close to uncovering important causal relationships between productivity growth and economic fluctuations: being itself

unemployment. (The labour market does not clear and the real wage is a decreasing function of the unemployment rate.) As unemployment decreases, real wage increases and the share of profits decreases accordingly. The economy thus enters a "recession" period where the growth in production capacities becomes less than the growth in labour supply. Unemployment then starts increasing again, thereby inducing a decrease in real wages. This in turn inverts the falling movement in profit share and thus announces a forthcoming acceleration of growth.

- Notable exceptions being Arrow (1962), Kaldor (1957), Shell (1973). 
directly inspired by the stochastic growth literature;' emphasising real productivity shocks as the source of economic fluctuations in order to account for the procyclical evolution of consumption and employment; its use of the Solow residual in order to measure the variations in capital or labour utilisation along the business cycle: all this was somehow predictive of (and was paving the way for) a forthcoming breakthrough. Such a breakthrough indeed occurred when R. King and S. Rebelo (1986) and G. Stadler (1988) in parallel generated an endogenous trend in real or monetary business cycles models.

\section{Introducing Endogenous Technical Change in Business Crcles Modek}

Existing business cycle models based on exogenous productivity or monetary shocks were unsatisfactory in several respects: first, they could not account for the existence of stochastic trends ${ }^{6}$ evidenced in empirical studies by Nelson-Plesser (1982) and CampbellMankiw (1987); second (and relatedly), aggregate demand shocks could have no lasting consequences on technology and growth; third, money had to remain neutral in the long-run, with monetary shocks being completely dichotomized in the long run from real technological shocks. Endogenising the growth process through the introduction of human capital investments as in King-Rebelo (1986) or of learning-by-doing as in Stadler $(1988,1990)$ did remove the above restrictive or counterfactual features for quite natural reasons which we shall now briefly review.

The remaining part of this section summarizes Stadler's contribution, even though the conclusions relative to the long-run growth effects of real productivity shocks are equally attributable to King-Rebelo (1986).

5 Starting with Brock and Mirman (1972).

6 That is, if the fact that aggregate output has a greater-than-unit root. 
The main idea underlying Stadler (1990) can be summarized as follows: a positive productivity shock [or a positive money supply shock with real temporary effects] due to nominal contractual rigidities à la Fischer (1977)-Taylor (1980) or to informational rigidities a la Lucas (1972) should induce a higher level of real economic activity in the short-run. Then, either because of learning-by-doing a la Arrow (1962) or as a result of more intense R\&D investments, ${ }^{7}$ there will be a burst of technological growth. Real income will in particular end up at a permanently higher level, even after individual expectations have fully adjusted to the initial monetary shock.

More formally, the individual output supply by any individual firm $i^{B}$ at time $t$ is given by the following Cobb-Douglas technology:

$$
Y_{t}^{\prime}=\operatorname{k} \cdot\left(L_{t}\right) \cdot\left(Z_{t}\right)^{1-e} F_{t},
$$

where $L_{i}^{i}$ is the amount of labour currently employed by firm $i, F_{1}$ is a positive productivity shock with both a temporary and a permanent component in it, and $\mathrm{Z}_{\mathbf{H}}$ is the accumulated aggregate knowledge in the economy. The evolution of this aggregate knowledge variable reflects total learning by doing from past aggregate employment, according to the dynamic equation:

$$
Z_{t}=Z_{t-1} \cdot\left[\frac{Y_{t-1}}{L_{t-1}}\right]^{\lambda}\left(L_{t-1}\right)^{\gamma}
$$

In words, a greater level of aggregate labour input $L_{1.1}$ and/or a higher productivity of labour

7 Implicitly, R\&D investments are more profitable during coonomic expansions and/or can then be more easily financed through retained eamings by otherwise cashconstrained research firms, as correctly pointed out by Stiglitz (1992).

- The economy comprises a large number of competitive firms all producing the same good as output. 
due to some efficient reorganization of production activities will both increase the rate of accumulation of knowledge.

Profit maximization subject to the technological constraint (1) defines a log-linear labour demand schedule?:

$$
l_{t}^{d}=a+b\left(p_{t}-w_{p}\right)+c f_{t}
$$

This, together with the labour supply schedule, which is also assumed to be log-linear $\left[r_{1}=\phi_{1}+\phi_{2}\left(w_{1}-p_{1}^{e}\right)\right]$ and depends on the expected equilibrium price as of time $t_{1}^{10}$ determines the equilibrium employment level $l_{1}=l_{1}=l_{t}$ and thus the following (log-linear) aggregate supply function (after substituting for $l_{1}$ in (1)):

$$
y_{t}^{\prime}=a^{\prime}+b^{\prime}\left(p_{t}-p_{t}^{\prime}\right)+C^{\prime} \cdot \eta_{t}+d^{\prime} \cdot f_{t-1}+e^{\prime} \cdot z_{t}
$$

where $\bar{f}_{t-1}$ is the $\log$ of the accumulated shock 10 productivity up to time $(t-1)$, and $\eta_{1}$ is the $\log$ of the real productivity shock at date $t$.

The model is then closed by postulating the following aggregate demand schedule, corresponding to a quantity theory equation with unit velocity:

$$
Y_{1}^{d}=\frac{M_{t}}{P_{t}} .
$$

where the money supply $M_{1}$ follows a random walk with positive drift:

$$
m_{t}=m_{t-1}+\mu+e_{t}
$$

with $m=\log M$ and $\epsilon$ being a zero-mean constant variance error term. The model is now

9 Small letters refer to the logarithms of the corresponding capital letters. All coefficients in the log-linear equations are taken to be positive.

10 Individuals ignore the true market price $p_{1}$ when entering into one-period fixednominal-wage contracts with firms at the beginning of period $t$. Thus they supply labour on the basis of the expected real wage $w_{1} / p_{i}^{e}$. 
completely specified: equation (5) implies that the price error (in log terms) is equal to the unexpected monetary shock $m_{1}-m_{1}^{e}=\epsilon_{1}$ minus the unexpected component of aggregate demand $y_{1}^{d}-y_{1}^{d e}$ (which, by market clearing, is also equal to $y_{1}^{*}-y_{1}^{*}=\Gamma\left(p_{1}-p_{l}^{e}\right)+c^{c} \cdot \eta_{1}^{11}$ ). The price-error term $p_{t}-p_{l}^{e}$ is then given by:

$$
p_{t}-p_{i}^{*}=\frac{1}{1+b^{2}}\left(e_{1}-c^{\prime} \eta_{1}\right)
$$

Overall, the equilibrium aggregate output $y_{1}$ is simply obtained from equation (4) by substituting for the price error term $p_{i}-p_{i}$ :

$$
y_{1}=a^{2}+\frac{b^{2}}{1+b^{2}}\left(e_{i}-c^{3} \cdot \eta_{1}\right)+c^{2} \cdot \eta_{i}+d^{2} \cdot f_{i-1}+e^{2} \cdot z_{1}
$$

The sources of non-stationarity in aggregate output are first the knowledge term $z_{1}$ (which depends upon past employment levels) and second the accumulated shock to productivity $\tilde{f}_{1-1}$. This model thus immediately delivers a stochastic trend component to aggregate output.

A special case of the above model is when unanticipated shocks are purely monetary: then, $\eta_{1}=0$ and aggregate output is simply given by:

$$
y_{1}=a^{2}+\frac{b^{2}}{1+b^{2}} \cdot e_{t}+e^{x} \cdot z_{t},
$$

where $z_{1}$ depends upon past values of output and employment levels through the accumulation of knowledge (or learning by doing) equation (2).

This implies that an unanticipated increase in money supply today, $\epsilon_{1}>0$, by increasing output and employment today, will also increase the level of knowledge $z_{1+1}$ tomorrow. This in tum will induce a further increase in aggregate output and employment

$11 \tilde{f}_{1-1}$ and $z_{1}$ are fully expected at the beginning of date $t$. 
tomorrow, thereby increasing $z_{+1}$, and so on. Output will thus grow at an increasing rate over time and thus will exhibit greater-than-unit roots in its stochastic evolution. Furthermore, this model generates a strong non-neutrality result: namely, the real impact on aggregate output of a temporary monetary shock increases over time as a result of learning by doing.

Another special case is when shocks are purely technological (i.e. $\epsilon_{\mathrm{t}}=0$ ). Again, as a result of leaming-by-doing, a (transitory) productivity shock will have durable (and even increasing over time) effects on aggregate output.

Let us conclude this section by mentioning what we believe are limitations of this otherwise successful attempt at explaining the trend in a business-cycle model. First, the model as it stands generates explosive growth ${ }^{12}$ and thus does not allow for a

12 Or explosive downturns if the initial shock on real output is negative! Note that this explosive growth result could have been avoided, had the elasticity of current knowledge $\left(z_{2}\right)$ with respect to past knowledge $\left(z_{-1}\right)$ been assumed to be less than 1 . To see this, it suffices to consider the following simplified version of Stadler's pure monetary model (obtained by setting: $\gamma=\lambda, a^{*}=0, e^{*}=b^{*} / 1+b^{*}$ and $\tilde{\epsilon}_{1}=e^{1} . \epsilon_{1}$, $\tilde{z}_{\mathbf{z}}=\mathrm{e}^{\prime} . \mathrm{z}_{1}$ in the above equations (2) and (8)):

$$
\begin{aligned}
& \bar{z}_{1}=\bar{z}_{-1}+\lambda y_{1-1} \\
& y_{1}=\bar{\epsilon}_{1}+\bar{z}_{1}
\end{aligned}
$$

Combining (2)' and (8)' yields the following reduced form equation:

$$
(1-(1+\lambda) \mathrm{L}) \mathrm{y}_{1}=\epsilon_{1} \quad \text { (where L. } \mathrm{y}_{1}=\mathrm{y}_{1-1} \text { ) }
$$

As a solution to this equation when $\epsilon_{\mathrm{t}}>0$ and $\epsilon_{r}=\alpha(r \geq t)$, aggregate output $y_{1}$ follows necessarily an explosive growth path since $1+\lambda>1$ ! Now, let us modify equation (2)' by assuming an elasticity of current knowledge w.r.t. past knowledge strictly less than 1 , equal to $1-\delta$ :

$$
\bar{z}_{1}=(1-\delta) \bar{z}_{1-1}+\lambda y_{t-1}
$$

The reduced form equation now becomes: 
parametrisation of the long-run trend as a function of business cycles characteristics. Second, productivity growth is assumed to be procyclical. As we have already discussed above, such an assumption can be justified as resulting from leaming-by-doing or demand spillovers, or as a consequence of capital market imperfections which constrain $R \& D$ investments to vary procyclically with current earnings. ${ }^{13}$ Furthermore, it is consistent with the observed procyclical behaviour of the Solow residual. On the other hand, a more recent theoretical and empirical literature has emphasized several countercyclical factors in the dynamics of productivity-growth over the business-cycle. [A pro-cyclical Solow Residual is not inconsistent with that view either, since the observed procyclicality may be equally due to supply shocks or mismeasurement, as pointed out by Hall (1990).] This countercyclical approach is being surveyed in the following section.

\section{On the Virtue of Bad Times}

The Schumpeterian view of business cycles (and particularly recessions) as providing a cleansing mechanism for reducing (or eliminating) organizational inefficiencies and resource misallocations, has been recently revived by several authors, including Hall (1991), GaliHammour (1991), Caballero-Hammour (1993), Dellas (1993), and Aghion-St. Paul (1991).

This view was summarized by Schumpeter himself in the following terms ${ }^{14}$ :

$$
(1-(1-\delta+\lambda) \mathrm{L}) \mathrm{y}_{\mathrm{t}}=(1-(1-\delta) \mathrm{L}) \epsilon_{\mathrm{t}} .
$$

One can now see that whenever $\delta<\lambda$, growth remains explosive; for $\delta>\lambda$, growth tapers off; and for $\delta=\lambda$, growth becomes asymptotically balanced at a positive (endogenous) rate.

13 See Stiglitz (1992) for a technical change model with credit-rationing.

14 This quote is drawn from Stiglitz (1992). 
"[Recessions] are but temporary. They are the means to reconstruct each time the economic system on a more efficient plan."

One can indeed think of several reasons why recessions could have positive effects on productivity: There is first the "cleaning-up" or "lame duck" effect emphasized by Schumpeter and recently formalized by Caballero-Hammour (1993), whereby less productive firms are eliminated during recessions and average productivity increases accordingly. This effect, however, may be offset by the fact that the rate of entry of new (efficient) firms is also lower during recessions, which in tum limits the extent of the phasing out of old (inefficient) firms. In the limit case where the entry cost is independent of the entry flow, fluctuations are entirely accommodated through entry and job destruction over time: it does not react to the business cycle. This is what Caballero-Hammour call the insulation effect. ${ }^{\text {is }}$ On the other hand, if the entry cost increases with the size of the entry flow, for example due

is More formally, let $A\left(t_{0}\right)$ denote the constant flow of output generated by a firm created at date $t_{0}$. Let $\bar{a}(t)$ be the maximum age of firms at date $t_{\text {. Assuming that }}$ each firm employs only one worker and that labour is the numeraire, the profit flow of a firm of age a at date $t$ is given by:

$$
\pi(a, t)=P(t) \cdot A(t-a)-1
$$

where $P(t)$ is the current price of output.

Therefore the obsolescence age $\bar{a}(t)$ is defined by:

Now suppose that $A(t)=A(0) \cdot e^{r t}$. The free-entry condition at time $t$ can then be expressed as:

$$
\begin{aligned}
c(f(0, t)) & =\int_{0}^{\bar{a}^{\prime}} \pi(a, t+a) e^{-r a} d a \\
& =\int_{0}^{\bar{a}^{\prime}} A\left(\bar{a}^{t}-a\right) e^{-r a} \cdot d a,
\end{aligned}
$$

$r$ being the interest rate and $\bar{a}^{t}$ being the lifetime of a firm entering at date $t$. When $c^{\prime}(f(0, t))=0$, i.e. $c(f(0, t))=C$, equation $(2)$ defines $\vec{a}^{-1}$ as a constant: i.e. the obsolescence rate of firms is independent of demand conditions (fluctuations). These must thus entirely be absorbed by the entry rate $f(0, t)$, in contrast to the case where $c^{\prime}(f(0, t))>>0$. 
to negative congestion externalities between the entering firms at a given point in time, the entry process will tend to be smoothed out over time: namely, firms will avoid entering during peak demand periods where the entry cost is likely to be higher. The insulation effect will then be partly neutralised and job destructions (corresponding to the exit of old inefficient firms) will tend to fluctuate more than job creations by new entering firms, in line with the empirical evidence provided by Davis-Haltiwanger (1991).

A second reason why recessions might have a positive impact on [long-run] productivity lies in the following "opportunity cost" or intertemporal substitution argument: Productivity-improving activities such as reorganizations or training often take place at the expense of directly productive activities (manufacturing). Since the retum to the latter is lower in recessions due to lower demand for the manufactured good, the opportunity cost in terms of foregone profits of "reorganization" activities will be lower in recessions than in expansions.

This idea has first been formalized by Hall (1991) who constructs a model where a constant labour force is allocated between production and the creation of organizational capital [in contrast to Real Business Cycles models where the altemative activities are production and leisure]. As a result of the opportunity cost argument developed above, more accumulation of "organizational capital" goes on during recessions: "Measured output may be low during (recession) periods, but the time spent reorganizing pays off in its contribution to future productivity".

Note that the "opportunity cost" approach applies primarily to investments which yield benefits over a long period of time (such as training, reorganization or machine 
replacement ${ }^{16}$ ). These are more likely to be countercyclical than say advertising investments which yield higher profits over a shorter period of time, namely during a current expansion phase. Cash-intensive investments such as R\&D are also more likely to be procyclical (due to credit-constraints of the kind emphasized by Stiglitz (1992)) than reorganization or training activities based to a larger extent on a redistribution of existing labour resources.

The "opportunity cost" approach appears to be supported by recent empirical work, primarily Bean (1990), Gali-Hammour (1991) and St. Paul (1992). All three find evidence of a long-run negative effect of a positive demand shock on productivity, ${ }^{17}$ thereby emphasizing reallocation effects as more important than the procyclical learning-by-doing (or demand spillover) effect described in the previous section. Bean (1990) goes on arguing that the opportunity cost approach can explain the procyclical behaviour of labour productivity: if firms allocate a larger share of their labour force to "reorganization" activities during recessions, then the actual input to productive activities go down by more than the observed labour input, hence accounting for the measured decrease in total factor productivity during

${ }^{16}$ See Cooper-Haltiwanger (1993), who construct a dynamic model where retooling activities involve non-convex costs and therefore tend to be concentrated during economic slowdowns or during periods of low productivity. Evidence of such "opportunity cost" behaviour is provided by interwar and post-war data on the US automobile industry, which show that machine replacements are concentrated during the summer months and sometimes extended to the adjacent months if the economy goes through a downtum.

17 Regressing productivity growth (measured by the Solow residual) on the business cycle (measured by the employment rate or the rate of capacity utilization), using US data over the sample period 1890-1987, Gali-Hammour (1991) find that a positive aggregate demand shock increases employment temporarily (by more than 2\%) but lowers productivity growth (by more than $1.4 \%$ ) in the long nun. Also, Saint-Paul (1991) finds a positive cross-country correlation in OECD countries between total factor productivity growth and unemployment over the 1974-90 period. 
recessions! ${ }^{18}$ Further evidence of an opportunity cost effect is provided by St. Paul (1992) who shows (using the same variant of Blanchard-Quah's VAR estimation method as GaliHammour) that the effect of demand fluctuations on productivity growth is stronger when demand fluctuations are more transitory. ${ }^{19}$

A third reason for why recessions should have a positive impact on productivity is the following "disciplinary" effect: recessions increase the likelihood of bankruptcy for firms that do not undertake the necessary reorganization investments. Aghion and St. Paul (1991) get this type of effect in the context of an "opportunity cost" model of cyclical growth by introducing fixed costs of production. ${ }^{20}$ Increases in firms' indebtedness should also reinforce the disciplinary effect of recessions, as argued in Nickell-Wadhwani-Wall (1992).

Finally, the following kind of "externality" effect pointed out by Dellas (1993) may also reinforce the countercyclical impact of recessions on average productivity: "If the difference in expected performance (between good and bad firms or workers) ... widens more

18 This provides one reason why the opportunity cost approach is not inconsistent with the observed "pro-cyclicality" of the Solow residual, the other being that some of the productivity-improving activities (like reorganization) may not be measured in the national accounts, a point emphasized by Bean (1990). A recent contribution by Burnside, Eichenbaum, and Rebelo (1993) analyses labour hoarding along the business cycle and concludes that it is a significant source of pro-cyclicality of the Solow residual. It is fair to say that when these two sources of pro-cyclicality are removed, there is no evidence left of a pro-cyclical Solow residual. Indeed, under the identifying assumptions made in Gali-Hammour and Saint-Paul, the evidence points to a counter-cyclical residual, in.

19 St. Paul (1992) also finds little evidence of any pro-or counter-cyclical behaviour of R\&D. The reason might be the cash-intensive nature of $R \& D$ which should partly offset the opportunity cost effect. Or it may just be due to the poor quality of aggregate R\&D data. Finally, the response of productivity growth to demand fluctuations explains a non-negligible (10-20\%) share of the variance of the Solow residual.

20 The basic framework developed in Aghion-St. Paul (1991) is outlined in the next section. 
than proportionally with the degree of adversity, then adverse conditions can help improve the selection process by reducing the probability of an occupational mistake." 21 A potential problem with this story is that the reverse effect should also obtain during expansions so that an increase in the frequency or magnitude of demand fluctuations might have no effect on the average rate of productivity growth. This problem can however be mitigated by assuming that the difference in relative performance between good and bad workers (or firms) is a nonlinear function of the activity level: namely, the relative performance of good workers is disproportionately high during recessions. This convexity assumption plays a similar role to Caballero-Hammour's assumption that the unit cost of entry increases during expansion periods together with the total number of entering firms.

Our discussion so far has emphasized the (potentially) positive effects of recessions on the average level of productivity.

The next step is to incorporate these effects into a dynamic framework where the impact of demand fluctuations on the average rate of productivity growth could be systematically analyzed. A first attempt in this direction is presented in the next section.

\section{Modelling the Ellects on Productivity Growth of} the Structure of the Business Cycle

(a) The basic set-up

Consider an economy which produces a variety of goods indexed by i, the demand for good i at time $t \in(0, \infty)$ being given by:

21 Such improvements in the selection of good firms during recessions are empirically supported by Dellas (1993) on the basis of a study of business closures in the US between 1947 and 1983, suggesting that business closures are a cenyex function of the degree of adversity and are therefore countercyclical. 


$$
D_{t}=\frac{y_{\mathrm{f}}}{P_{\mathrm{r}}}\left(\frac{p_{\mathrm{ir}}}{P_{\mathrm{f}}}\right)^{-\eta} .
$$

where $y_{t}$ is an aggregate demand index, $p_{i x}$ is the price of good $i$, and $p_{1}$ is an aggregate price index defined by the usual formula:

$$
p_{1}=\left(\int_{0}^{N_{1}} p_{n}^{1-\eta}\right)^{1 / 1-\eta}
$$

( $n>1$ and $N_{1}$ denotes the number of varieties produced at time $t$ ).

Each good $i$ is assumed to be supplied by a monopolist whose production (or employment) capacity is fixed. At any point in time $t$ each firm $i$ is characterized by a

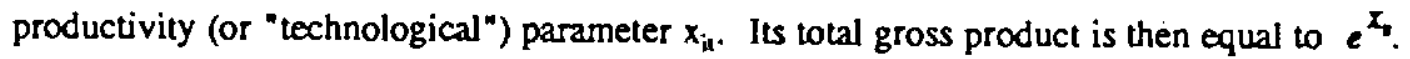
Let $v_{b}=\frac{d x_{t}}{d t}$ denote the speed of productivity improvement: it is assumed to be a choice variable of firm i, who will constantly trade-off the cost of a higher speed of "tochnological" progress (in terms of foregone current profits) against future gains in NPV due to a higher productivity parameter $x$ in the future. We consider two alternative assumptions regarding the cost of productivity improving activities:

ASSUMPTION A: In order to grow at rate $v_{i n}$ the firm must sacrifice a fraction $k\left(v_{i n}\right)$ of its production. We assume $\mathbf{k}^{\prime}=0, \mathbf{k}^{\prime \prime}>0, \mathbf{k}^{\prime}(0)=0$.

ASSUMPTION B: In order to grow at rate $v_{\text {in }}$ the firm must buy a quantity $h\left(v_{i k}\right)$ of aggregate output. We assume $h^{\prime}=0, h^{*}>0, h^{\prime}(0)=0, h^{\prime}(+\infty)=+\infty$.

Assumption A describes a world (world A) a la Hall (1991) where productivity improvements have disruptive effects on production. This may happen if at the time when new technologies are implemented, the firm's managers and skilled workers must be trained in order to leam the new technology, and if at the same time the firm cannot find other 
workers to perform their current production tasks.

By contrast, assumption B describes a world à la Stiglitz (1992) where productivity growth can be "bought" on the market (e.g. in the form of R\&D services) without interfering with current production tasks. ${ }^{22}$

In both worlds, the net output of firm $i$ is given by:

$$
z_{k}=e^{x_{2}} \cdot \phi_{k} \text {. }
$$

where $\phi_{i r}$ is equal to $1-k\left(v_{i b}\right)$ in world $A$ and to 1 in world $B$. The market equilibrium price $p_{i t}$ which matches the supply of good $i$ defined by (3) with the demand for good $i$ defined by (1) is then simply given by:

$$
p_{i}=y_{i}^{1 / \pi} \cdot p_{i}^{1-1 / \pi} \cdot e^{-x / \pi} \cdot \phi_{i}^{-1 / \pi}
$$

We shall be interested in symmetric equilibria where $x_{i x}=x_{1}$ and $v_{i n}=v_{1}$ for all firms i $\epsilon[0, N]$. In such equilibria the equilibrium price $p_{\text {it }}$ will be the same for all firms and equal to:

$$
p_{i}=y_{1} \cdot e^{-x_{1}} / N_{1} \cdot \phi_{1} \text {. }
$$

The corresponding flows of current profits will then be:

$$
\pi_{k}=p_{b} \cdot z_{k}=\frac{y_{t}}{N_{t}} \text { in world A }
$$

and

$$
\pi_{k}=p_{k} \cdot z_{k}-h(v)=\frac{y_{t}}{N_{t}}-h\left(v_{p}\right) \text { in world } \mathrm{B} .
$$

22 An alternative interpretation of assumptions $A$ and $B$ is in terms of labour adjustment costs. In world $\mathrm{A}$, hiring and firing workers is very costly so that it is desirable for the firm to stick to its current labour force, be it employed in directly productive or in productivity improving activities. In world $\mathrm{B}$, hiring and firing costs are very low so that the firm can hire extra workers to perform productivity-improving activities. 
Our description of the basic set-up will now be complete once we can determine the equilibrium speed of productivity growth $v_{1}$ and the equilibrium number of varieties $N_{1}$ at any time $t$.

First, the equilibrium number of firms $N_{1}$ is determined by entry and exit conditions. We assume a fixed cost of entry equal to C. Thus, whenever the expected NPV or market value of an entering firm, $V_{1}$, is greater than $C$, the number of firms $N_{1}$ increases up to the point where $V_{1}$ is exactly equal to $C .{ }^{23}$ Concerning exit, we assume that any incumbent firm that exits the market can recoup a liquidation value equal to $\theta \mathrm{C}$ in symmetric equilibrium, ${ }^{24}$ with $\theta \leq 1$. Then, an incipient drop in the market value $V_{1}$ below $\theta C$ triggers exit until $V_{1}$ increases up to the exit value $\theta C$. If $\theta<1$, we have $\frac{d N_{1}}{d t}=0$ whenever $V_{1} \in[\theta \mathrm{C}, \mathrm{C}]$.

Finally, the optimal speed of productivity improvement $v_{1}$ is determined as follows: Let $V_{1}\left(x_{i l}\right)$ denote the market value at time $t$ of firm $i$ where current productivity level is $x_{i n}$. If $r$ denotes the interest rate at which firms can freely borrow and lend, the market value $V_{t}$ satisfies the following Bellman equation:

$$
V_{t}\left(x_{i j}\right)=\max _{v}\left\{\pi_{i j} \cdot d t+(1-r d t) E_{i} V_{1-d t}\left(x_{i j}+v d t\right)\right\}
$$

where $E_{1}$ denotes the expectation operator as of time $t$. The firm's optimal policy $v_{\text {in }}$ is then simply the argmax of the RHS of (6), and it satisfies the first-order condition:

23 Like the profits flows that it capitalizes, the net present value $V_{1}$ is also decreasing in the number of goods $\mathrm{N}_{1}$.

24 More generally, we assume that the liquidation value is equal to $\theta C e^{B\left(x_{4}-x\right)}$, where $\beta$ is chosen in such a way that an increase in productivity $x_{i n}$ has the same marginal impact on the continuation value and in the exit value. Proceeding otherwise introduces an "exit effect" which is analyzed in Aghion-St. Paul (1993). 


$$
-\frac{\partial \pi_{k}}{\partial \nu}=E_{i} \cdot \frac{\partial V_{t+d}}{\partial x}
$$

where $\frac{\partial \pi_{k}}{\partial v}=-p_{t} \cdot e^{x_{*}} \cdot k^{\prime}\left(v_{t}\right)$ in world $A$,

$$
=-h^{\prime}\left(v_{b}\right) \quad \text { in world } B \text {. }
$$

The basic set-up is now fully specified; the next step is to introduce demand fluctuations and then analyze their impact on average productivity growth.

\section{(b) Introducting economic fuctuations}

We formalize economic fluctuations as a two-state stationary Markov process where aggregate demand $y_{1}$ is altematively high equal to $y_{E}$ (the subscript $E$ refering to an "expansion") or low equal to $y_{R}$ (the subscript $R$ refering to a "recession"). Transitions from one state to another follow a Poisson process whereby with flow probability $\gamma$ the economy drops from $E$ to $R$ and the reverse transition occurs with flow probability $\epsilon$.

We are looking for a stochastic steady-state where all variables (except $x$ and $p$ ) are constant in each state. Let $v_{j}, \pi_{j}, v_{j}$ with $j \in\{E, R\}$ be the values taken by $v_{1}, \pi_{1}, v_{1}$ in state j. The Bellman equation (6) in such a stochastic steady-state boils down to the following system:

$$
\left\{\begin{array}{l}
V_{R}(x)=\max _{V}\left\{\pi_{R} d t+(1-r d t)\left[V_{R}(x+v d t)(1-e d t)+V_{E}(x+v d t) e d t\right]\right\} \\
V_{E}(x)=\max _{V}\left\{\pi_{R} d t+(1-r d t)\left[V_{E}(x+v d t)(1-\gamma d t)+V_{R}(x+v d t) \gamma d t\right]\right.
\end{array}\right.
$$

The equilibrium speeds of productivity growth $v_{R}$ and $v_{E}$ (respectively in recession and in expansion) are simply the argmax corresponding to the above two equations, and thus satisfy both (8) and the first-order condition (7). Letting $d t \rightarrow 0$ in (8); then using the first-order 
condition ( 7$)$ after having substituted for $\frac{\partial V}{\partial x} ;{ }^{2 s}$ finally using the fact that:

$$
\pi_{j}=\frac{y_{j}}{N_{j}}=d_{j} \text { in world } \mathrm{A}
$$

and

$$
\pi_{j}=\frac{y_{f}}{N_{j}}-h(\nu)=d_{j}-h(v) \text { in world } \mathrm{B},
$$

we obtain the following simple system of equations which fully determine the rate of productivity growth $v_{j}$ in each state $j$ :

1) In world $\mathrm{A}$ :

$$
\left\{\begin{array}{l}
d_{E} \cdot k^{\prime}\left(v_{\varepsilon}\right) / 1-k\left(v_{\varepsilon}\right)=\frac{(r+e) d_{E}+\gamma d_{R}}{r(r+e+\gamma)} \\
d_{R} \cdot k^{\prime}\left(v_{R}\right) / 1-k\left(v_{R}\right)=\frac{(r+\gamma) d_{R}+e d_{E}}{r(r+e+\gamma)}
\end{array}\right.
$$

where $d_{j}=\frac{y_{j}}{N_{j}}$ measures individual firms' demand level in state $\mathrm{j}$.

The LHS of (9a) are the opportunity costs of reallocating workers from directly productive to productivity improving activities respectively in states $j=E$ and $R$. These are proportional to $d_{j}$, the current state of demand: therefore, the higher current demand, the larger the foregone profits from shifting labour force into productivity improving activities. The RHS of (9a) are the present discounted values of the gain flows from such reallocation in states $E$ and $R$ respectively. Because these gains are reaped over the whole future including both expansion and recession periods, it is not surprising that the RHS of (9a)

25 The derivation of $\frac{\partial V_{1}}{\partial x}$ itself uses the Bellman equation (6) reexpressed as (8). We have, from $\quad(6): \quad \frac{\partial V_{t}}{\partial x}=\frac{\partial \pi_{t}}{\partial x} \cdot d t+(1-r d t) E_{t} \frac{\partial V_{i+d}}{\partial x}, \quad$ where
$\frac{\partial \pi_{t}}{\partial x}=(1-1 / \eta) p_{t} r_{i t}=(1-1 / \eta) \pi_{u}$ from $(3)$ and $(4)$. 
appear as a weighted average of $d_{E}$ and $d_{R}$.

Now suppose that individual firms' demand is higher in expansion than in recession: that is, $d_{E}>d_{R}$. (This tums out to be the case if $\theta<1$.) ${ }^{26}$ Then the above system (9a) implies that productivity growth is higher in recession than in expansion. i.e. $v_{R}>y_{E}$, in accordance with Hall (1991). ${ }^{27}$ The intuition for this result relies entirely on the opportunity cost argument developed in the previous section: In world $\mathrm{A}$, the opportunity cost of productivity improvement is given by the marginal current foregone revenue. It is therefore higher in expansions than in recessions. On the other hand, the gain from this action is also higher in expansions than in recessions, but it is spread over the whole future which includes both expansion and recession phases. The gain is therefore less cyclical than the cost. As a result the optimal rate of productivity growth $v_{j}$ is counter-cyclical.

2) In world B:

26 Assuming that recessions are sharp enough to induce exit, we have: $V_{E}=C$ and $V_{R}$ $=\theta \mathrm{C}$. Substituting for these values in Bellman equations (8) and letting $\mathrm{dt} \rightarrow 0$, we get:

$$
\pi_{E}=d_{E}=(r+\gamma(1-\theta)) C
$$

and $\pi_{R}=d_{R}=(r \theta+\epsilon(\theta-1)) C$.

So that indeed $d_{E}>d_{R}$ whenever $\theta<1$.

27 Indeed, (9a) can be rewritten:

and

$$
k^{\prime}\left(v_{E}\right) /\left(1-k\left(v_{E}\right)\right)=\frac{(r+\epsilon)+\gamma d_{R} / d_{E}}{r(r+\epsilon+\gamma)}
$$

$$
k^{\prime}\left(\nu_{R}\right) /\left(1-k\left(v_{R}\right)\right)=\frac{(r+\gamma)+e d_{d} / d_{R}}{r(r+e+\gamma)}
$$

Given that the LHS are identical and increasing in $v$, and that the RHS of (1) is larger than that of (2), it is clear that $v_{E}<v_{R}$. Q.E.D. 
(9b)

$$
\left\{\begin{array}{l}
h^{\prime}\left(v_{E}\right)=\frac{\eta-1}{\eta} \cdot \frac{(r+e) d_{E}+\gamma d_{R}}{r(r+e+\gamma)} \\
h^{\prime}\left(v_{R}\right)=\frac{\eta-1}{\eta} \cdot \frac{(r+\gamma) d_{R}+e d_{E}}{r(r+e+\gamma)}
\end{array}\right.
$$

One can then show that when the cost function $h(v)$ is sufficiently convex and $\theta<1$, productivity growth is procyclical, i.e. $v_{E}>v_{R}{ }^{2 s}$ The economic intuition here works as follows: in world $\mathrm{B}$, the marginal cost of productivity-improving activities only depends on $v$ and is otherwise unaffected by the business-cycle. On the other hand, when evaluating the present discounted gains from such activities, firms will put more weight on future expansion states if currently in expansion than if currently in recession. The result then follows from the fact that whenever entry costs are not fully recouped upon exit $(\theta<1)$ firms' revenues from a productivity improvement are larger in expansion than in recession.

\section{c) Effects of economic fluctuations on leng-nun growth}

It is now very easy to compute the average growth rate of the economy. Note that the economy grows at rate $v_{E}$ in expansions and $v_{R}$ in recessions, and that in stochastic steady-state, it spends a fraction $\epsilon / \gamma+\epsilon$ of time in expansion and the complementary fraction

2s Again assuming that recessions are sufficiently sharp to induce exit, so that $V_{E}=C$ and $V_{R}=\theta C$, we have in world $B$ :

$$
d_{E}=(r+\gamma(1-\theta)) C+h\left(v_{\varepsilon}\right)
$$

and $d_{R}=(r \theta+\epsilon(\theta-1)) C+h\left(v_{R}\right)$.

Plugging these expressions back into ( $9 \mathrm{~b}$ ) establishes our claim provided $\theta<1$ and the function $g$ defined by:

$$
g(v)=h^{\prime}(v)-(\eta-1) h(v) / n(r+\epsilon+\gamma)
$$

is increasing in $v$. This in turn is automatically true when $h(v)$ is sufficiently convex. 
in recession. Thus the average growth rate $\mathrm{g}$ is simply given by:

$$
g=\frac{\gamma}{Y+e} \cdot v_{R}+\frac{e}{Y+e} v_{E} .
$$

One can now study, in worlds $A$ and $B$, how the average growth rate $g$ is affected by variations in the magnitude $d_{E} / d_{R}{ }^{29}$ and the frequency (measured by $Y$ and/or $\epsilon$ ) of economic fluctuations.

Here, we shall only briefly deal with the growth effects of variations in the frequency of fluctuations. ${ }^{30}$ Three growth effects of a variation in $\gamma$ and/or $\epsilon$ can actually be sorted out:

(a) A composition effect apparent from equation (10): if the frequency of recessions $y$ increases (or that of expansions $\epsilon$ decreases), the economy will spend more time on average in recession. As a result growth $g$ will tend to increase in world $A$ where $v_{R}>$ $v_{E}$, and to decrease in world $B$ where $v_{E}>v_{R}$.

(b) A retum effect, which comes out of equation (9a) or (9b): given that we typically have $d_{E}>d_{R}$, an increase in the frequency of recessions $Y$ tends to lower the average return to productivity-improving activities, thereby decreasing both rates $v_{E}$ and $v_{R}$. (Similarly if $\epsilon$ decreases.)

(c) A cost of capital effect, which comes from the terms $(r+\gamma(1-\theta)) C$ and $(r \theta+\epsilon(\theta-1)) C$ in the expressions of $d_{E}$ and $d_{R}$. An increase in $Y$ increases $d_{E}$ and therefore

29 I.e. variations in $\theta$ when exit occurs in recession or in $y_{E} / y_{R}$ if no exit occurs in recession.

30 If exit occurs in recessions the amplitude of firm level fluctuations is insulated from that of aggregate fluctuations. A change in the amplitude of the business cycle is therefore fully met through an equivalent change in $\mathrm{N}_{\mathrm{E}} / \mathrm{N}_{\mathrm{R}}$ with all other variables, including $v_{E}$ and $v_{R}$, unaffected. Therefore a change in the amplitude of the cycle as no effect on growth. This is why we focus on the frequency effects in the remainder of the paper. See Aghion-St. Paul (1993) for a more comprehensive analysis of the growth effects of the magnitude and frequency of economic fluctuations. 
tends to speed up productivity growth in both states, the intuition being as follows: because entry costs are not fully recouped upon exit, firms make a capital loss whenever the economy shifts from expansion to recession. Therefore, the higher $\gamma$, the larger the present discounted capital loss evaluated by a firm that decides to enter during an expansion phase. The larger the current profit of such firm $d_{E}$ must then be for entry to take place at all.

The cost of capital effect disappears when $\theta$ is so small that no exit occurs in recession. Then, we immediately get that in world $B$ an increase in the frequency of recessions will have a negative effect on average productivity growth. In world $A$ one can show that the composition effect dominates when the initial frequency of recessions is low whereas the retum effect dominates when the initial frequency is high: $\frac{d g}{d \gamma}>0$ when $\gamma_{0}$ small and $\frac{d g}{d \gamma}<0$ when $\gamma_{0}$ large. [Converse effects obtain from an increase in the frequency of expansions $\epsilon$.]

In the opposite case where entry costs are nearly recouped upon exit $(\theta-1)$, the structure of the business cycle $(\theta, \epsilon, \gamma)$ tums out to have no first-order effect on long-run growth in world A: that is, the above three effects tend to cancel each other out. However, the same result as above [namely $\frac{d g}{d \gamma}>0$ iff $\gamma_{0}$ small] obtains in the range of second-order effects. In world $\mathrm{B}$, however, one can show that the cost-of-capital effect never outweighs the composition and retum effects, so that $\epsilon$ and $\gamma$ always have the following (non-surprising) first-order effects on growth: $\frac{d g}{d \gamma}<0$ and $\frac{d g}{d e}>0$.

Using OECD data for 22 countries between 1950 and 1988, St. Paul (1992) first confirms the empirical conclusions obtained by Gali-Hammour (1991) that countercyclical effects of the "world A" type are likely to prevail. Second, by regressing the average growth rate on indicators of the frequency of fluctuations, St. Paul shows that high frequency components of fluctuations seem to have a negative effect on long-run growth, while low 
frequency components tend to have a positive effect. ${ }^{31}$

These results support the general message that the structure of the business-cycle may affect long-run growth. However, the specific predictions generated above [e.g. concerning the growth effects of variations in the frequency of recessions and expansions] tumed out to depend on the relative magnitudes of $\gamma$ and $\epsilon$ and on the extent to which exits would occur in recessions. These theoretical predictions are still awaiting the construction of adequate empirical tests. ${ }^{32}$

\section{From Growth to Business Crcles: the Schumpeterian Waves Revisited}

Our focus so far has been on the growth effects of economic fluctuations. What about the converse causality from growth to fluctuations and cycles? We do not know of any empirical work addressing this latter relationship, however the recent neo-Schumpeterian literature provides some theoretical benchmarks that could serve as a basis for future tests and analysis.

A first benchmark is provided by Aghion-Howitt (1992), whose creative destruction model boils down to a first-difference negative relationship between current and future research in perfect foresight equilibrium:

31 See Table 1 in Appendix, where GYD is the rate long-run productivity growth, $T(0,9)$ is an index of the transitory nature of demand shocks, SP4 (resp. SP1) is the proportion of the variance of demand shocks explained by frequency components whose period is between 2 and 4 years (respectively more than 16 years). The SP4 coefficients are negative whereas the SPI coefficients are positive.

32 Hamilton (1989) has estimated a two-state Markov process for the American business cycle (see also Acemoglu and Scott (1992)). A promising direction for future research would be to estimate such processes for a cross-section of countries and correlate their parameters with long-run productivity growth. This would allow for more direct tests of the above analytical results. 


$$
n_{r}=\psi\left(n_{r+1}\right), \quad \psi^{\prime}<0
$$

where $n_{1}$ is the amount of labour devoted to R\&D after the $t^{\text {th }}$ innovation has occurred. In words, the more research is expected to occur following the next innovation the shorter the likely duration of the monopoly power to be enjoyed by the next innovator and hence the smaller the payoff to current research. ${ }^{33}$ This difference equation can be shown in many cases to have periodic solutions of order two in addition to the steady-state (or "balanced growth") solution $\hat{n}=\Psi(\hat{n})$. In these periodic solutions, the amount of labour devoted to research oscillates regularly between a high and a low level, thereby generating a syclical growth pattem.

Secondly, whether in steady-state or on a cyclical path, the endogenous growth process remains stochastic, reflecting the uncertainty of the innovation process. ${ }^{34}$ In steadystate the log of output can be shown to follow a random walk with drift, in accordance with recent empirical studies emphasizing the random nature of the economic trend (e.g. Campbell-Mankiw (1989)).

A third, more recent, line of research has been to explore the existence of heterogeneities in the innovation process and in particular the dichotomy between fundamental innovations (or "breakthroughs") and secondary innovations (or "improvements"). By focusing on this dichotomy between breakthroughs and increments, Jovanovic and Rob (1990) in a partial equilibrium context and more recently Cheng and Dinopoulos (1992) in a general

33 An additional reason for the negative dependency of current research $\mathrm{n}_{\text {, }}$ upon future research $n_{1+1}$ is the fact that higher demand for future research labour will push future wages $w_{1+1}$ up, thereby decreasing the flow of profits to be appropriated by the next innovator.

34 This uncertainty however disappears at the aggregate level if the economy consists of a continuum of independent sectors pursuing i,i,d innovation processes. (See Grossman-Helpman (1991) and Aghion-Howitt (1992).) 
equilibrium framework, have been able to generate the so-called Schumpeterian waves where each fundamental innovation is followed by a sequence of more and more incremental adaptations.

Of particular interest as a macroeconomic model is the Cheng-Dinopoulos (1992) paper where Schumpeterian waves obtain as a unique [non steady-state] equilibrium solution, along which the current flow of monopoly profits follows a cyclical evolution. "Because the economy's wealth is equal to the discounted present value of aggregate monopoly profits, fluctuations in profits generate procyclical fluctuations in wealth, the interest factor, consumption, (...) and aggregate R\&D investments." (Cheng-Dinopoulos.)

The basic set-up can be summarized as follows: the economy comprises $\mathrm{n}$ industries, each of them allowing for a countably infinite set of successive [product] generations. A generation is a sequence of quality improvements of decreasing size $\alpha_{0}>\alpha_{1} \ldots>\alpha_{k}$, and it is brought about by a "breakthrough".

As in previous quality ladders models, all goods in a given industry are perfect substitutes once we adjust for quality, and the profit flow of the leading monopoly firm is increasing in the size of the quality improvement this firm introduces. Therefore, the lower the ranking of a quality improvement (i.e. the higher $j \in\{0, \ldots, K\}$ ), the lower the corresponding discounted monopoly profits.

The key assumption of the paper concerns the comparative costs of the two linds of innovative activities (fundamental and secondaries).

Cheng and Dinopoulos suppose that all secondary innovations involve the same cost $h(R)$ expressed as the duration of the R\&D race required to discover (or implement) the innovation, $R$ being the aggregate $R \& D$ investment in the race. Since the discounted monopoly profits generated by successive secondary innovations decreases with their ranking 
$\mathrm{j} \in\{0, \ldots, \mathrm{K}\}$, it becomes less and less profitable to devote $R \& D$ resources to secondary improvements $j$ as $j$ increases. Then, if $h_{0}(R)$ denote the cost, again in terms of the duration of the corresponding patent race, of generating a fundamental breakthrough, the basic assumption of the paper is simply that:

$$
h_{0}(R)>h(R) \text {. }
$$

Thus, in turn, may suffice to generate Schumpeterian waves: immediately following a fundamental breakthrough that has already brought about a quality improvement of size $\hat{\alpha}_{0}$, if $\hat{\alpha}_{1}$ is sufficiently close to $\hat{\alpha}_{0}$ then it is more profitable to invest $R \& D$ resources in the $\mathrm{j}=1^{*}$ secondary improvement than in a new fundamental breakthrough because of (2) above. However, for $j$ sufficiently large (and hence $\hat{\alpha}_{j}$ sufficiently close to 1 ), it becomes profitable to race for a new fundamental breakthrough. ${ }^{35}$ This cyclical pattern of innovations in turn generates deterministic fluctuations in real output around its growth trend. ${ }^{36}$

Other research lines also deserve to be investigated: One line, suggested by CooperHaltiwanger (1993), would be to investigate whether business cycles can result from the existence of strategic complementarities or (demand) spillovers between multiple producers, each of them following an "s-S" policy in the adoption of new equipments. (Such lumpy adoption process in tum would follow from non-convexities in the retooling tochnology.)

35 This is particularly true if the cost of implementing a new breakthrough decreases with the length of time, $r$, since the last breakthrough: $h_{0}=h_{0}^{*}(R, r)$, with $h_{0 r}^{\circ}<0$. See Cheng-Dinopoulos (1992).

36 An interesting outcome of this multi-industry model concerns the different patterns that can be followed by the cyclical wave; either intraindustry where the fundamentalsecondary sequence takes place within a single industry before being reproduced elsewhere; or interindustry where breakthroughs diffuse across industries before the first improvements appear. 


\section{References}

Aghion, P. and P. Howitt, "A Model of Growth through Creative Destruction", Econometrica, 60 (1992): 323-51.

Aghion, P. and G. St. Paul, "On the Virtue of Bad Times". unpublished, DELTA, Paris (1991).

Arrow, K., "The Economic Implications of Leaming by Doing". Review of Economic Studies, 29 (1962): 155-73.

Bean, C., 'Endogenous Growth and the Procyclical Behaviour of Productivity", European Economic Review, 34 (1990): 355-63.

Brock, W. and L. Mirman, "Optimal Economic Growth and Uncertainty: The Discounted Case", Joumal of Economic Theory, 4 (1972): 479-513.

Caballero, R. and M. Hammour, "The Cleansing Effect of Recessions", NBER Working Paper (1991), forthcoming in the American Economic Review.

Campbell, J. and G. Mankiw. "Are Output Fluctuations Transitory?", Quarterly Joumal of Economics (1987): 857-880.

Cheng, L. and E. Dinopoulos, "A Schumpeterian Model of Economic Growth and Fluctuations", Mimeo (1992), University of Florida.

Cooper, R. and J. Haltiwanger, "The Aggregate Implications of Machine Replacement: Theory and Evidence", American Economic Review, No.3, 83 (1993): 360-380.

Dellas, H., "Recessions and Ability Discrimination", Mimeo (1993), University of Maryland.

Domar, E., "Expansion and Employment", American Economic Review, 37 (1947).

Fischer, S., "Long-term Contracts, Rational Expectations and the Optimal Money Supply Rule", Joumal of Political Economy, 85 (1977): 191-205.

Gali, J. and M. Hammour, "Long-run Effects of Business Cycles", Mimeo (1991), University of Columbia, New York.

Goodwin, R-M., "A Growth Cycle", in Feinstein (eds.), Capitalism and Economic Growth, Cambridge, (1967): 54-58.

Grandmont, J.M., "On Endogenous Competitive Business Cycles", Econometrica, 53-5 (1985): 995-1045. 
Grossman, G. and E. Helpman, "Quality Ladders in the Theory of Growth", Review of Economic Studies, 58 (1991): 43-61.

Hall, R., "Recessions as Reorganizations", (1991), NBER Macro Annual.

Hicks, J. (1950)

Jovanovic, B. and R. Rob, "Long Waves and Short Waves: Growth through Intensive and Extensive Search", Econometrica, 58 (1990): 1391-1409.

Kaldor, N., "A Model of Economic Growth", Ecconomic Journal, 67 (1957).

Kalecki

King, R. and S. Rebelo, "Business Cycles with Endogenous Growth", (1986), Mimeo.

Kydland, F. and E. Prescott, "Time to Build and Aggregate Fluctuations", Econometrica, 50 (1982): 1345-1370.

Long, J. and C. Plosser, "Real Business Cycles", Lournal of Political Economy, 91 (1983): $1345-1370$.

Lucas, R., "Expectations and the Neutrality of Money", Loumal of Economic Theory, 4 (1972): 103-124.

Muet, P.A., "Croissance et Cycles", Economica (1993).

Nelson, C. and C. Plosser, "Trends and Random Walks in Macroeconomic Times Series: Some Evidence and Implications", Journal of Monetary Economics, 10 (1982): 139 162.

Nickell, S., Wadhwani, S. and M. Wall, "Productivity Growth in U.K. Companies, 19751986", European Economic Review, 36 (1992): 1055-1085.

Saint-Paul, G., "Productivity Growth and the Structure of the Business Cycle", European Economic Review, (1993).

Shell, K., "Inventive Activity, Industrial Organization, and Economic Activity", in Models of Economic Growth, ed. by J. Mirrlees and N. Stern (1973), London McMillan.

Solow, R., "A Contribution to the Theory of Economic Growth", Quarterly Journal of Economics, 70 (1956): 65-94.

Stadler, G., "Business Cycle Models with Endogenous Technology", American Economic Review, 80 (1990): 763-778. 
Stiglitz, J., "Endogenous Growth and Cycles", NBER Working Paper No.4286 (1993).

Taylor, J., "Aggregate Dynamics and Staggered Contracts", Joumal of Political Econemy, 88 (1980): 1-23. 


\section{Appendix}

Table 1 : Crowth Regrescions (s pand (1952))

Dependent varlable: GYD

\begin{tabular}{|c|c|c|c|c|c|c|}
\hline Independent & (1) & (2) & (3) & (4) & (5) & $(6)$ \\
\hline \multicolumn{7}{|l|}{ Vurlables: } \\
\hline \multirow[t]{2}{*}{ C } & 3.69 & 2.44 & 3.19 & 2.48 & 2.47 & 2.91 \\
\hline & $(5.06)$ & $(3.56)$ & $(5.00)$ & $(3.35)$ & $(5.07)$ & $(4.87)$ \\
\hline \multirow[t]{2}{*}{ YD65 } & -0.05 & -0.086 & -0.05 & -0.40 & -0.49 & -0.43 \\
\hline & $(-0.95)$ & $(-1.71)$ & $(-1.01)$ & $(-6.32)$ & $(-10.5)$ & $(-13.8)$ \\
\hline \multirow[t]{2}{*}{ SE } & 0.01 & -0.00 & 0.00 & 0.05 & 0.05 & 0.05 \\
\hline & $(0.88)$ & $(-0.27)$ & $(0.27)$ & (5.83) & $(4.78)$ & $(6.03)$ \\
\hline
\end{tabular}

$T(0.9)$

$-2.42$

$-0.65$

$(-2.65)$

$(-0.52)$

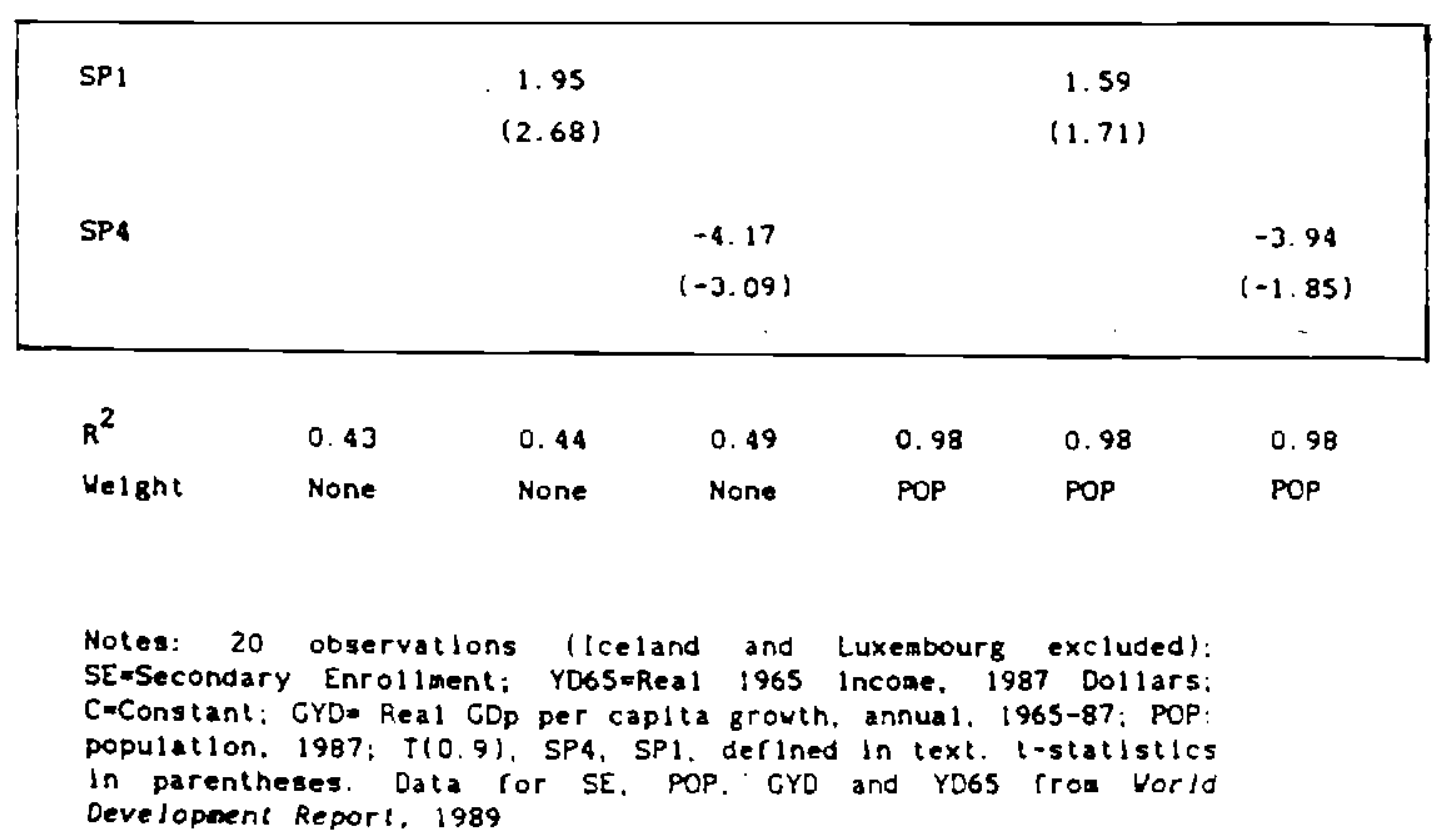

